http:/ /dx.doi.org/10.30747/bfgez.67.2017.12

\title{
CICHOCIEMNI. HISTORIE BOHATERÓW
}

Już po raz 26 Fundacja Generał Elżbiety Zawackiej zorganizowała konferencję naukową upamiętniającą działania niepodległościowe Polaków w XX w. Tym razem obrady naukowe, a także warsztaty historyczne dla młodzieży poświęcone zostały "Cichociemnym”. W przeddzień konferencji, przy współpracy JW GROM, Fundacja zorganizowała spotkanie z ostatnim żyjącym cichociemnym, kpt. Aleksandrem Tarnawskim. Na spotkanie, oprócz zaproszonych nauczycieli i młodzieży, przybyła Maria Kowalewska „Myszka” - uczestniczka Powstania Warszawskiego.

Spotkanie prowadził Jan Wyrowiński, przewodniczący Rady Fundacji, który podziękował panu kapitanowi za przybycie, nawiązał do nazwy roku 2016 ustanowionego przez Sejm RP „Rokiem Cichociemnych”, wyraził też uznanie dla kapitana nie tylko z powodu służby, ale i aktualnych dokonań. Kapitan Tarnawski bowiem w 70. rocznicę swego wojennego skoku wykonał ponownie skok spadochronowy, tym razem w asyście żołnierzy JW 2305, którzy także podczas spotkania towarzyszyli bohaterowi. Spotkanie z ostatnim żyjącym cichociemnym było dużym przeżyciem dla wszystkich zebranych, szczególnie dla przybyłej młodzieży.

Konferencję, którą zaplanowano na 9 listopada, już tradycyjnie rozpoczęto od złożenia kwiatów na grobie gen. Elżbiety Zawackiej o godz. 9. Kwiaty złożyli oprócz delegacji Fundacji: Prezydent Miasta Torunia, przedstawiciele władz wojewódzkich i powiatowych, Instytutu Pamięci Narodowej oraz szkoły toruńskie noszące imię gen. E. Zawackiej.

Po złożeniu kwiatów na grobie gen. E. Zawackiej i krótkiej przerwie kawowej Jan Wyrowiński otworzył w Sali Wielkiej Dworu Artusa sesję naukową: "Cichociemni. Historie bohaterów". Powitał gościa honorowego sesji, kpt. Aleksandra Tarnawskiego i towarzyszącego mu płk. Piotra Gąstała, dowódcę JW GROM, Michała Zaleskiego, Prezydenta Miasta Torunia, Józefa Ramlaua, Wicewojewodę Bydgoskiego, Kazimierza Wacha, Prezesa Światowego Związku Żołnierzy AK Okręg Toruń, Jerzego Janczarskiego, Dyrektora Wydziału Kultury Urzędu Marszałkowskiego Województwa Kujawsko-Pomorskiego, Edytę Ciesielską, Naczelnik bydgoskiej delegatury Instytutu Pamięci Narodowej Bydgoszczy, Dorotę Zawacką-Wakarecy, prezes zarządu Fundacji Generał Elżbiety Zawackiej, prelegentów, licznie przybyłą młodzież z opiekunami i wszystkich obecnych.

O zabranie głosu został poproszony kpt. Aleksander Tarnawski. Dziękując za zaproszenie i podkreślając zaszczyt, za jaki poczytuje sobie obecność na sesji, zaapelował o pamięć o tych anonimowych dziew- 
czętach i chłopcach, którzy oddali życie za Ojczyznę, a o których się nie pamięta.

Wicewojewoda Józef Ramlau w krótkiej wypowiedzi nawiązał do osobistych kontaktów z gen. Elżbietą Zawacką, którymi się szczyci, i zaapelował do młodzieży o szersze zainteresowanie historią, zwłaszcza związaną z obroną Polski w czasie II wojny światowej. Prezydent Michał Zaleski powiedział, że XXVI konferencja naukowa potwierdza tezę, że w Toruniu dbamy o historię. Gen. Elżbieta Zawacka była nie tylko dzielną wojowniczką, ale też pedagogiem. O bohaterach powinno się mówić często i głośno. Podziękował Dorocie Zawackiej-Wakarecy za te spotkania. Podziękował również Muzeum II Wojny Światowej, IPN i Centrum Kultury „Dwór Artusa” w Toruniu.

Głos zabrał także płk Piotr Gąstał, który odnosząc się do wyjątkowości cichociemnych, podkreślił, że współcześnie tylko ci żołnierze GROM, którzy przejdą selekcję i ponadroczne szkolenie podstawowe $\mathrm{w}$ wielu formach nawiązujące do szkolenia cichociemnych (zaliczą pozytywnie wszystkie egzaminy), mogą zostać nazwani cichociemnymi i dumnie nosić naszywkę „Cichociemny” zatwierdzoną decyzją Ministerstwa Obrony Narodowej. Jako ostatnia w tej części głos zabrała pieśniarka Caty Carr, popularyzująca historię Polski za pomocą swojej twórczości, co ważne - także anglojęzycznej.

Obradom konferencji przewodniczyli kolejno: dr Janusz Marszalec, prof. dr hab. Andrzej Gąsiorowski, dr Katarzyna Minczykowska i prof. dr hab. Bogdan Chrzanowski. Natomiast referaty kolejno prezentowali: mgr Igor Oraczewski z UMK: "Cichociemni a komandosi”, dr K. Minczykowska (FGEZ), stawiając pytanie, czy „Gen. Elżbieta Zawacka. Cichociemna?"; mgr Wojciech Łukaszun (Instytut Historii UG/Muzeum II Wojny Światowej w Gdańsku): „Narcyz Łopianowski, ps. »Sarna«. Kawalerzysta, sportowiec, cichociemny. Dużą atrakcją dla zebranych gości było wystąpienie kpt. Paweła Mosznera, byłego żołnierza JW GROM i wojskowego instruktora spadochronowego, twórcy barw i odznaki GROM, a także działacza Klubu Spadochronowego Sił Specjalnych. Zaprezentował on bowiem zrekonstruowany kombinezon Special Operations Executive (SOE), którego używali cichociemni. Z pomocą jednej z uczestniczek konferencji dokonał praktycznego pokazu zakładania kombinezonu i spadochronu. Zebrani mogli sobie uświadomić, w jaki sposób cichociemni, w tym i inicjatorka fundacyjnych konferencji E. Zawacka - przygotowywali się do skoku, a następnie go wykonywali. Następna prelegentka dr Ewa Rzeczkowska (Katedra Historii Najnowszej KUL) przedstawiła referat „Leonard Zub-Zdanowicz „Ząb” - jedyny cichociemny w Narodowych Siłach Zbrojnych", a dr Dominika Pasich (IPN Kraków) omówiła działalność Antoniego Gilewskiego „Ponara” 


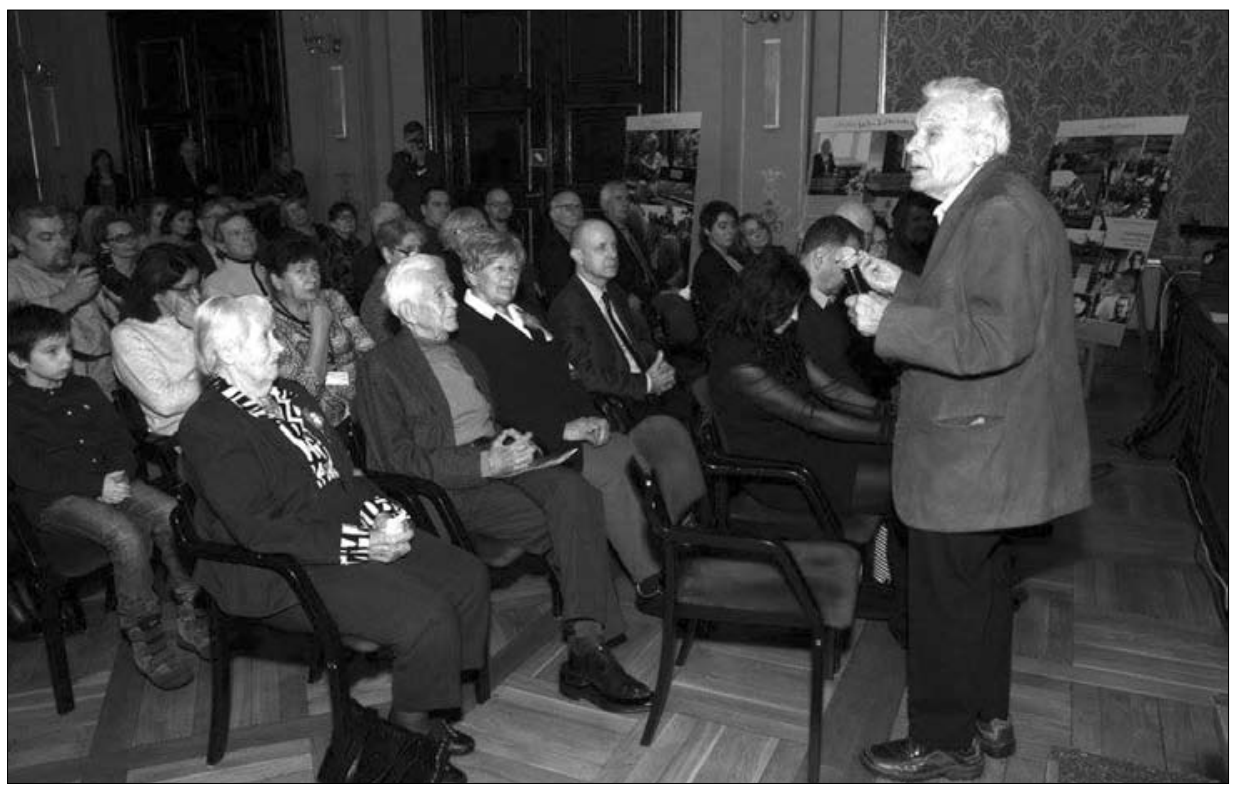

Fot. 1. Ostatni żyjący cichociemny, kpt. Aleksander Tarnawski „Upłaz”, „Wierch" przemawia do gości sesji (fot. R. Stasiak, zb. FGEZ)

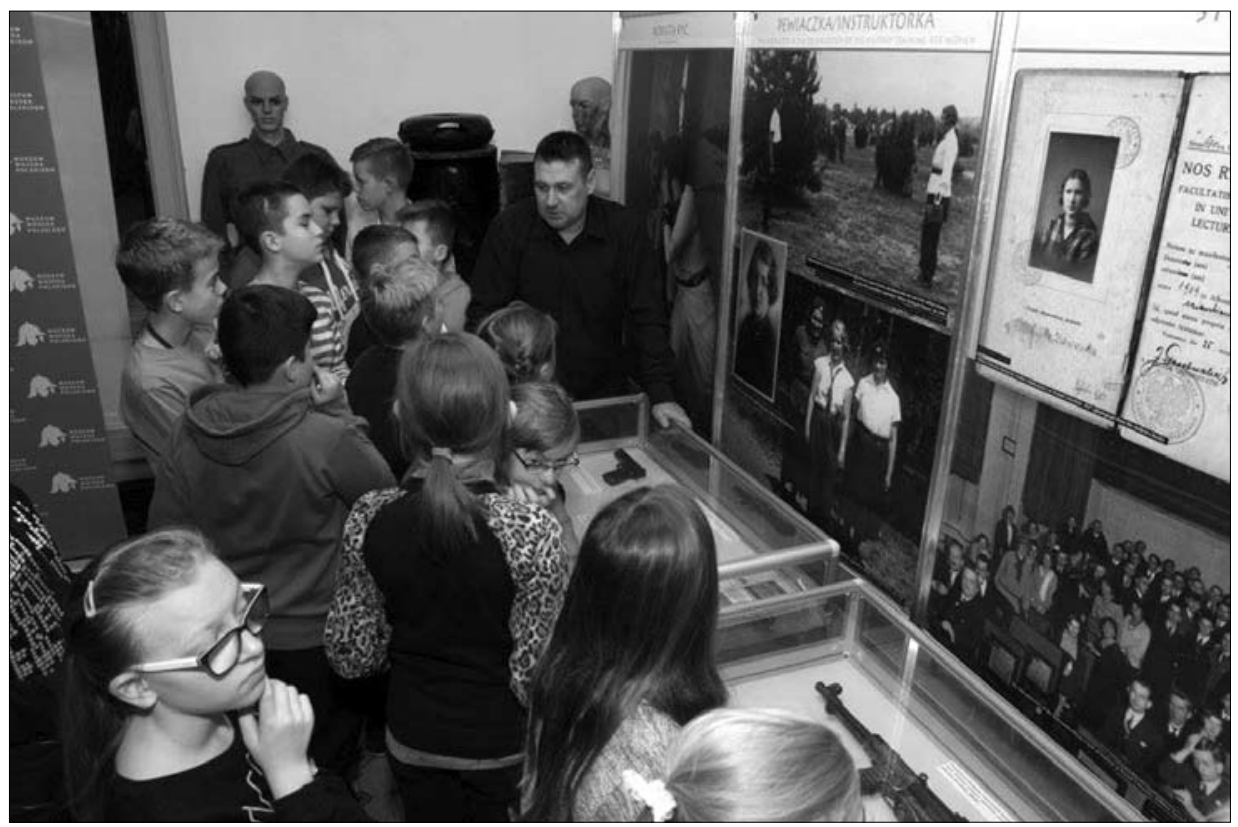

Fot. 2. Jeden z warsztatów odbywających się w trakcie sesji (równolegle z konferencją naukową). Prowadzenie Michał Olton, Muzeum Wojska Polskiego, Warszawa (fot. R. Stasiak, zb. FGEZ) 
- cichociemnego z Radziejowa. Za swą bogatą działalność, prowadzoną od 17. roku życia, 16 XII 1948 r. został on aresztowany przez UB i skazany, na podstawie fałszywych dokumentów na 15 lat więzienia. Wyszedł na wolność na mocy amnestii w 1956 r. Zmarł w roku 1979. Jego grób znajduje się w pobliskim Radziejowie Kujawskim. Dr hab. Maciej Kledzik (Uniwersytet Warmińsko-Mazurski) przygotował referat "Cichociemny Kazimierz Bilski »Rum «", na temat londyńskiego współpracownika Elżbiety Zawackiej i ostatniego "cichociemnego" przerzuconego do kraju przed wybuchem Powstania Warszawskiego. Referat, z powodu nieobecności autora, odczytał prof. A. Gąsiorowski. Grzegorz Andrzej Hanula (Muzeum Żołnierzy Wyklętych i Więźniów Politycznych PRL) przedstawił referat "Cichociemni zamordowani w więzieniu mokotowskim”. W roku 1902 więzienie na Mokotowie było najnowocześniejszym więzieniem w Rosji carskiej. Zajmowało ono obszar 6 ha. Po zakończeniu wojny mokotowskie więzienie było miejscem kaźni polskiej elity intelektualnej, byłych żołnierzy AK i cichociemnych. Prelegent oszacował, że zostało tam wykonanych i udokumentowanych 350 egzekucji, setki zaś wykonano, nie pozostawiając śladów w dokumentacji. Według G. Hanuli szacuje się, że w latach stalinowskich w Mokotowie zamordowano ponad 2000 osób. Jako ostatnia podczas sesji głos zabrała Małgorzata Koszarek (Muzeum Armii Krajowej w Krakowie), omawiając „Pamiątki po cicho-

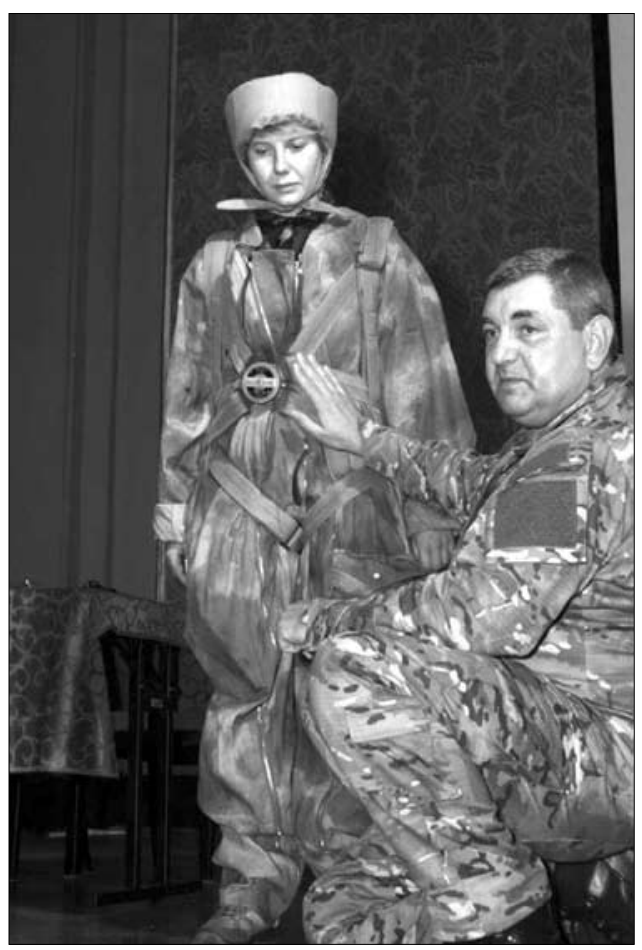
ciemnych w zbiorach Muzeum AK w Krakowie" oraz przedstawiając postaci wybranych cichociemnych, m.in. Jana Górskiego, ps. Chomik, pomysłodawcy szkolenia na Wyspach polskich żołnierzy, którzy mieli wesprzeć struktury wojskowe Polskiego Państwa Podziemnego.

Obrady naukowe składały się z czterech części, a każda była zakończona dyskusją, w której

Fot. 3. Paweł Moszner, były żołnierz Grupy Reagowania Operacyjno-

-Manewrowego (GROM) i wojskowy instruktor spadochronowy, prezentuje w przerwie obrad naukowych, zrekonstruowany kombinezon i spadochron, jakiego używali cichociemni (fot. R. Stasiak, zb. FGEZ) 
głos zabrała m.in.: Anna Zakrzewska, podając informację o cichociemnych rekrutujących się z Toruńskiej Szkoły Artylerii, powstałej w roku 1923. W szkole tej do 1939 r. odbyło się 16 promocji. Dwunastu polskich artylerzystów z Torunia było cichociemnymi. Większość została zamordowana, czy to jeszcze w czasie wojny przez Niemców, czy też tuż po niej przez funkcjonariuszy Urzędu Bezpieczeństwa.

Równolegle do części naukowej konferencji odbywały się warsztaty historyczne dla dzieci i młodzieży. Organizatorzy do współpracy zaprosili edukatorów z całej Polski. Swoje umiejętności zaprezentowali: Mateusz Gawlik (Muzeum AK w Krakowie) - „Cichociemni - spadochroniarze AK"; Joanna Raftopolus i Artur Wodziński (Muzeum II Wojny Światowej w Gdańsku) - "Cichociemni”; Mirosław Sprenger (Biuro Edukacji Publicznej IPN w Bydgoszczy) - "Cichociemni - »straż przednia« wyzwolenia Polski”; Michał Olton (Muzeum Wojska Polskiego), który zaprezentował elementy wyposażenia cichociemnych oraz współczesnych spadkobierców ich idei, żołnierzy GROM.

Barbara Rojek

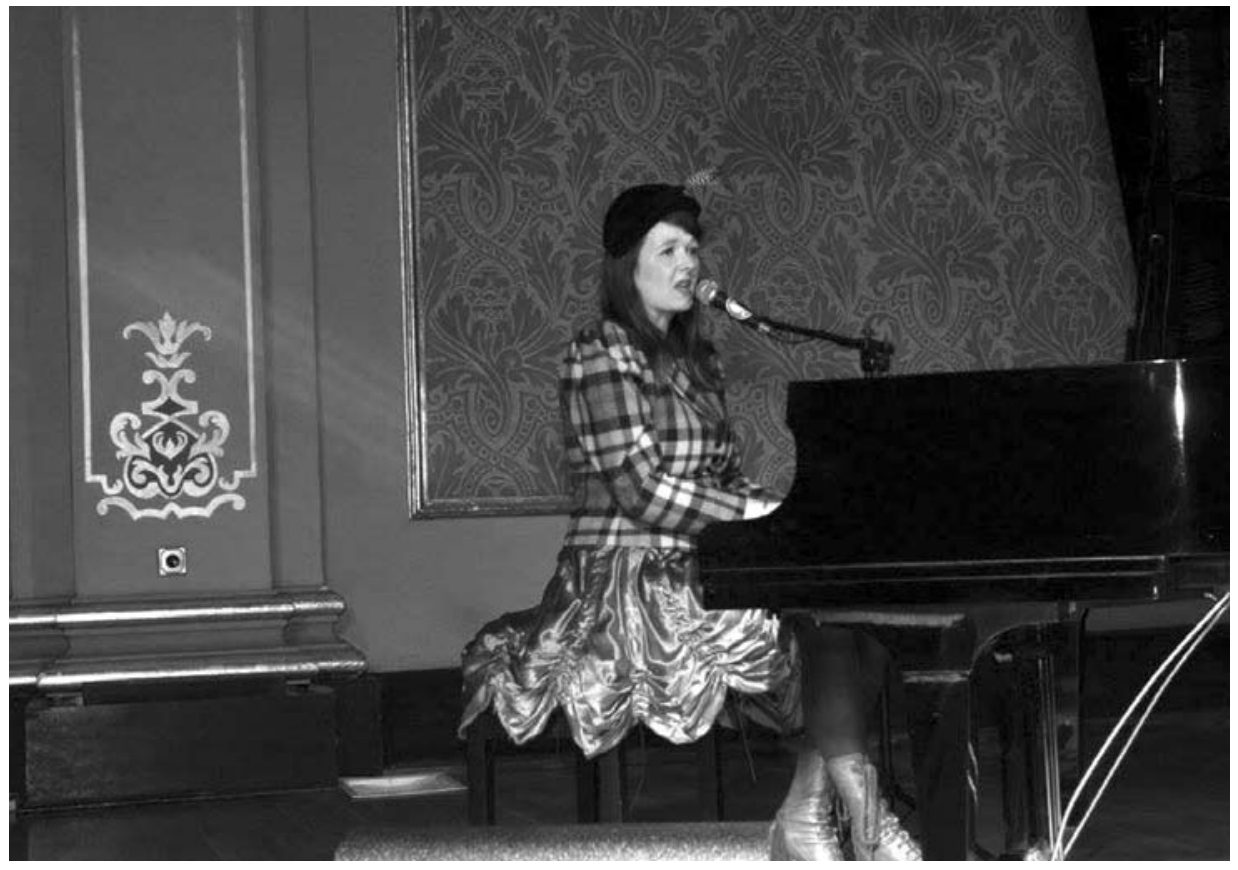

Fot. 4. Koncert Katty Carr, brytyjskiej pieśniarki, której twórczość poświęcona jest historii Polski, uświetniający sesję (fot. R. Stasiak, zb. FGEZ) 